\title{
URAKAL ADENOKANSER
}

\author{
URACHAL CARCINOMA
}

\section{Hakan YETIMALAR \\ Burcu KASAP \\ Külal ÇUKUROVA \\ Aşkın YILDIZ \\ Adnan KEKLIKK \\ Ferit SOYLU \\ Rukiye Mine TUNAKAN ÖZTOP}

\section{ÖZET}

Urakal adenokanserler kötü prognozla seyreden oldukça nadir görülen tümörlerdir. Olgu sunumumuzda 48 yaşındaki karın ağrısı şikayetiyle başvuran bir bayan hastada umblikus altına kadar uzanan yumuşak doku kitlesi palpe edildi. Bilgisayarlı Tomografi'de $13 \times 10 \mathrm{~cm}$ boyutlarında solid ve kistik alanlar içeren kitle görünümü mevcuttu. Tümör cerrahi olarak çıkartıldı. Laparatomi esnasında overler ve tubalar olağan olarak izlendi ancak kitle ile uterus serozası arasında yaygın yapışıklıklar mevcuttu Hastaya total abdominal histerektomi ve bilateral salpingooferektomi operasyonu uygulandi. Patoloji sonucu urakal adenokarsinom olarak gelen kitle haricinde uterus diş yüzeyinde de urakal adenokarsinom infiltrasyonu tesbit edildi. Hastanın 2 yıllık takibinde nüks kitleye rastlanmadı. Urakus, urogenital sinüs ve allantoisin embriyolojik kalıntısıdır. İnvolüsyon doğumdan önce tamamlanır ve urakus median umblikal ligament olarak kalır. Urakal tümörlerin patogenezi halen tam olarak aydınlatılamamıştır. Pelvik kitle öntanısıyla cerrahiye alınan hastaların prognozunda yandaş tedavilerin yeri ise tartışmalıdır

Anahtar Kelimeler: Urakal Adenokanser, laparatomi, cerrahi

\section{SUMMARY}

Urachal carcinoma is an uncommon neoplasm associated with poor prognosis. A soft abdominal mass palpated below the level of umblicus in 48 year old woman admitted by the complaints of abdominal pain in our case report. CT scan revealed a mass of $13 \times 10 \mathrm{~cm}$ consisted of solid and cystic components. Tumor was removed surgically. Ovaries and uterine tubes were normal but adhesions were present between the mass and uterine serosa. Total abdominal hysterectomy and bilateral salphingoopherectomy was performed. Pathology was revealed urachal adenocarcinoma and there was urachal adenocarcinom infiltration on the uterine serosa too. The recurence was not detected in 2 years follow up. The urachus is the embryological remnant of urogenital sinus and allantois. Involution usually happens before birth and urachus is present as a median umbilical ligament. The pathogenesis of urachal tumours is not fully understood until now. The role of adjuvant theraphy is not clearly understood at the prognosis of the patients who diagnosed and underwent surgery with pelvic mass.

Key Words: Urachal carcinoma,laparatomy,surgery

İzmir Atatürk Eğitim ve Araştırma Hastanesi

3. Kadın Hastalıkları ve Doğum Kliniği

(Op. Dr. H. Yetimalar, Op. Dr. B. Kasap, Op. Dr. K. Çukurova, Op. Dr. A. Yıldız, Op. Dr. A. Keklik)

2. Kadın Hastalıkları ve Doğum Kliniŏi

(Op. Dr. F. Soylu)

1. Patoloji Kliniği

Doç. Dr. R. Mine T. Öztop 


\section{GíRiş}

Urakal adenokanser kötü prognozla seyreden oldukça nadir tümörlerdir. Genel popülasyondaki tahmini yıllık insidansı 5 milyonda bir olup erişkin kanserlerinin \%0,01'ini oluşturmaktadır. Urakal kanserlerin tüm mesane kanserlerinin \%0.17-0.34'ünü oluşturduğu tahmin edilmektedir [1]. Bu vaka sunumunun amacı, pelvik kitle ön tanısıyla opere edilen ve patoloji sonucu urakal adenokarsinoma olarak tesbit edilen hastanın kemoterapi ile devam eden tedavi sürecini literatür bilgileri eşliğinde tartışmaktır.

\section{OLGU}

48 yaşındaki bayan olgu son 6 aydır devam eden karın ağrısı şikayetiyle kliniğimize başvurdu. Hastanın fizik muayenesinde umblikusa kadar uzanan yumuşak doku kitlesi palpe edildi.

BT'de sağ adneksiyal alanda $13 \times 10 \mathrm{~cm}$ boyutlarında solid ve kistik alanlar içeren kitlesel bir oluşum tesbit edildi (Şekil 1). Ca-125 değeri 401,2 mU/L ve Ca 153'ü 89,51 mU/L olan hastaya laparatomi uyguland1. Gözlemde hastanın sağ adneksiyal alanında mesane üzerine ve retziusa fikse heterojen içerikli 10x12x16 cm'lik kitle izlendi. Overler ve tubalar olağan görünümdeydi. Hastaya total abdominal histerektomi ve bilateral salpingooferektomi operasyonu uyguland1. Patoloji sonucu urakal adenokarsinom olarak gelen kitle de ayrıca uterus dış yüzeyinde de urakal adenokarsinom infiltrasyonu tesbit edildi (Şekil 2). Hastaya postoperatif dönemde $6 \mathrm{kez}$ cisplatin $75 \mathrm{mg}$, cyclophosphamide $750 \mathrm{mg}$, doxorubicin $75 \mathrm{mg}$ kemoterapi protokolü uygulandi. 2 yıl sonraki takiplerinde hastanın $\mathrm{Ca} 125$ değeri 20,9 U/mL olarak bulundu ve kontrol BT'sinde nüks kitleyle uyumlu bulguya rastlanılmadi.

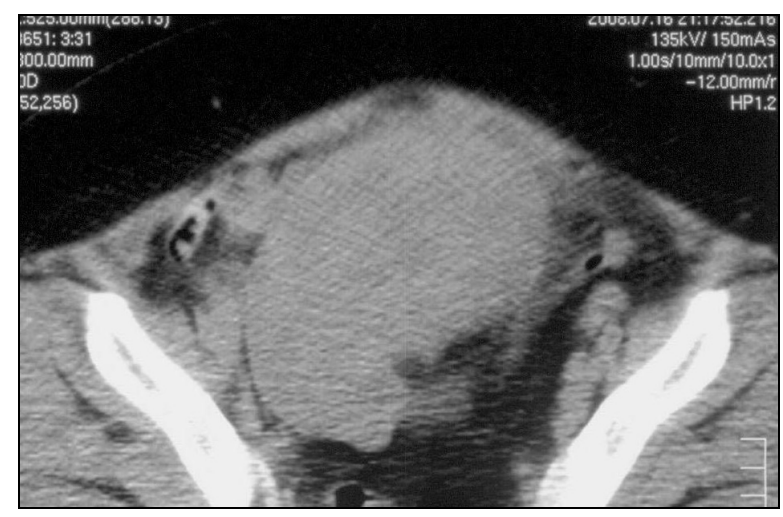

Şekil 1. BT-görüntüsü: mesane kubbesinden mesane posterioruna ve peritona doğru uzanan umblikus boyunca ilerleyen yumuşak doku kitlesi.
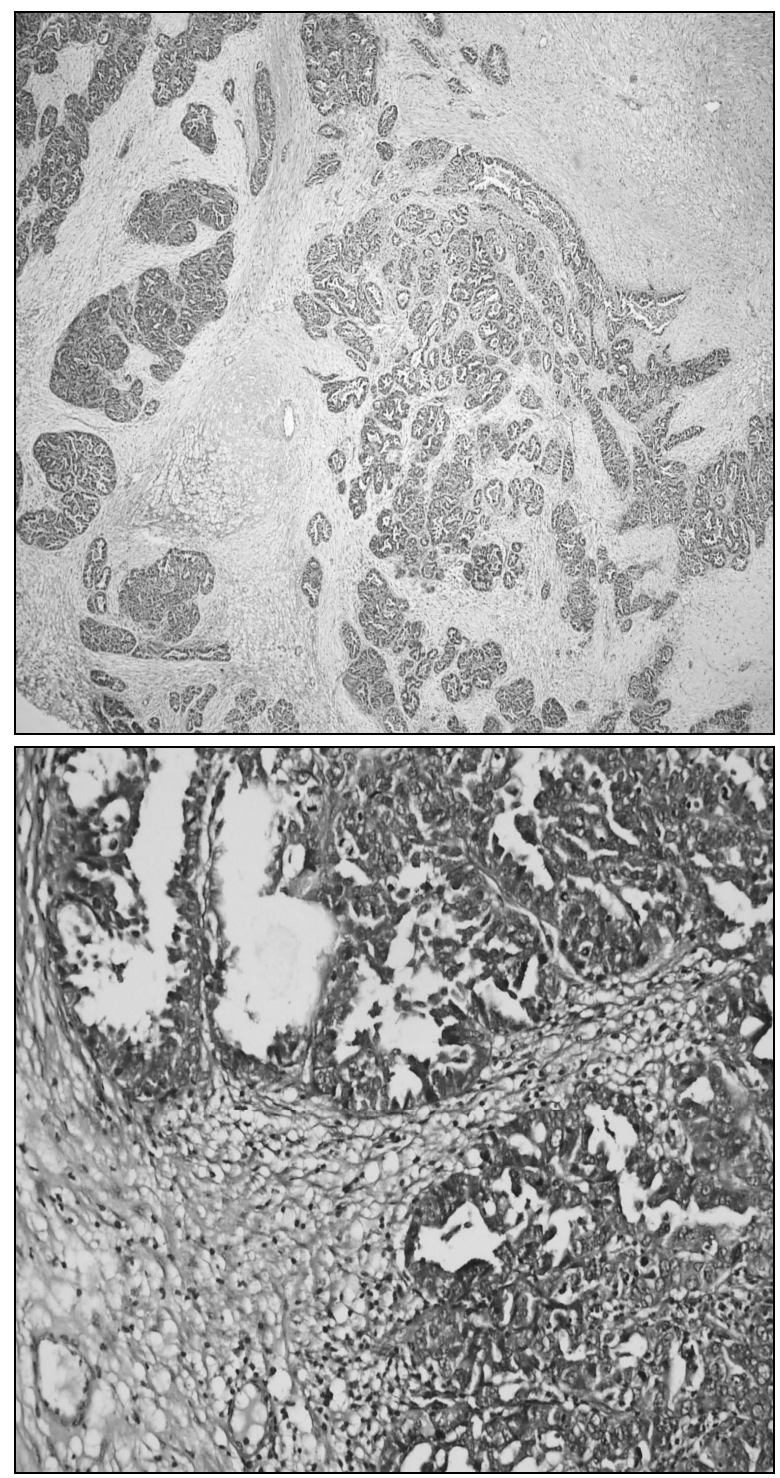

Şekil 2. Primer urakal karsinoma (H\&E, X12.5).

\section{TARTIŞMA}

Urakal Adenokarsinom \%65-75 oranla erkeklerde daha sık görülürken vakaların $\% 65$ 'i 40 ila 70 yaşları arasında izlenmektedir (2). Urakus karsinomlarında en sık rastlanılan bulgu hematüriolup, $\% 70$ oranında görülmektedir. Daha az rastlanılan bulgular ise karın ağrısı, suprapubik kitle, idrar yapma zorluğu, ve umblikustan mukus, püy veya kan gelmesidir (2). Ultrason ve BT'de izlenen soliter orta hat yumuşak doku kitlesi solid, kistik ya da karışık yapıda olabilir (2). Orta hat kitlelerinde yapilan doppler ultrasonun da tanıda önemli yeri mevcuttur (3). Urakus içindeki kitlenin ve umblikusun parsiyel ya da total sistektomi 
ile en blok rezeksiyonu en önemli tedavi seçeneğidir. Tedavi protokolüne eklenen radyoterapi hastalık seyrini etkilemezken, bazı yayınlarda eş zamanlı kemoterapinin de kullanıldığı belirtilmektedir (4). Urakus adenokarsinomlarının cerrahi tedaviden sonra lokal rekürrensi oldukça yaygındır. Uzak metastazlar daha geç görülür ve sıklıkla rejyonel lenf nodlarında, omentumda, karaciğerde, akciğerlerde ve kemiklerde yer alırlar (4). Uzun dönem prognozları mesanenin çoğu primer karsinomalarından daha kötüdür ve 5 yıllık sağkalım \%10 ila \%43 arasında değişmektedir (1). Urakus karsinomlarında uzun dönem prognoz sadece tümör grade'ine değil ayrıca tümörün ilk evresine de bağlı olduğu için bu nadir kötü huylu tümörde en kritik nokta tanının erken konulma durumudur (5).

\section{SONUÇ}

Olgumuzda tanı preoperatif olarak konulamamıştır. Hastanın hematürisinin olmaması ve BT sonuçlarında urakusla ilgili bulgu saptanmaması nedeniyle preoperatif sistoskopi yapılması planlanmamıştır. Tanı patoloji raporu ile konulmuş ve kemoterapi kararı alınmıştır. Literatürde urakus kanserleri ile ilgili yayınlar genelde olgu sunumu şeklinde ya da sınırlı sayıda olgudan oluşan serilerdir. Bundan dolayı cerrahi yaklaşım konusunda net bir sonuca ulaşmak mümkün değildir. Cerrahi tedavi yaklaşımlarını karşılaştıran randomize, prospektif bir çalışma yoktur. Bu yüzden literatür eşliğindeve olgunun klinikopatolojik özelliklerine göre tedavi yaklaşımı hasta ile de tartışılarak kararlaştırılmalıdır. Bu nadir kötü huylu tümör preoperatif overyal kitle öntanısı ile operasyona girilen vakalarda akılda tutulması gereken bir patolojidir. Operasyon sonrasında hastaların takipleri Üroloji ve Tıbbi Onkoloji işbirliği ile yürütülmelidir.

\section{KAYNAKLAR}

1. El-Ghobashy A, Ohadike C, Wilkinson N, Lane G, Campbell JD. Recurrent urachal mucinous adenocarcinoma presenting as bilateral ovarian tumors on cesarean delivery. Int J Gynecol Cancer. 2009; 19:1539-1541.

2. Ohira S, Shiohara S, Itoh K, Ashida T, Fukushima M, Konishi I. Urachal adenocarcinoma metastatic to the ovaries: case report and literature review. Int J Gynecol Pathol. 2003;22:189-193.

3. Oyar O, Yesildag A, Gulsoy UK, Perk H. The image of urachus adenocarcinoma on Doppler ultrasonography. Eur J Radiol. 2002 Oct;44(1):48-51.

4. Gopalan A, Sharp DS, Fine SW, Tickoo SK, Herr HW, Reuter VE, Olgac S. Urachal carcinoma: a clinicopathologic analysis of 24 cases with outcome correlation. Am J Surg Pathol. 2009; 33 (5):659-68.

5. Canda A.E., Mungan M.U., Tuna B., Yörükoğlu K., Kırkalı Z. Genç Bir Hastada Urakus Kanseri: Olgu Sunumu. Türk Üroloji Dergisi: 31 (1): 146-149, 2005.

\section{ILETiŞiM}

Op. Dr. Burcu KASAP

Gsm: 0.5052711056 